\title{
Effects of Caffeine on In-Vitro Fertilization of Pig Follicular Oocytes
}

\author{
Taku NAGAI ${ }^{1)}$, Katsuhiro MIURA ${ }^{2)}$, \\ Kazuhiro KIKUCHI ${ }^{3)}$, and Naomichi OKAMURA ${ }^{4)}$ \\ ${ }^{1)}$ Department of Animal Production, \\ Tohoku National Agricultural Experiment Station, Morioka, Iwate 020-01, \\ ${ }^{2)}$ Department of Resource Biology, \\ Faculty of Agriculture, Ibaraki University, \\ 3998 Amimachi Inashikigun, Ibaraki 300-03, \\ 3) National Institute of Agrobiological Resources Tsukuba, Ibaraki 305, and \\ 4)Institute of Basic Medical Sciences, University of Tsukuba, \\ Tsukuba, Ibaraki 305, Japan
}

\begin{abstract}
Experiments were conducted to assess the effects of caffeine on the ability of frozenthawed boar epididymal spermatozoa to penetrate oocytes that had been matured in culture. The spermatozoa were preincubated in modified TCM199 medium and subsequently incubated for $2 \mathrm{~h}$ in either a fertilization medium with $2 \mathrm{mM}$ caffeine or in a fertilization medium without caffeine. Then a sample of the spermatozoa in the caffeine-containing medium was introduced into another caffeine-containing medium that contained matured oocytes, while another sample was introduced into a medium with matured oocytes without caffeine. This procedure was repeated for the spermatozoa that had been incubated in the caffeine-free medium. The two sets of manipulations resulted in higher rates of penetration of oocytes inseminated in the caffeine-containing medium than of oocytes in the caffeine-free medium. Furthermore, when oocytes with attaching spermatozoa were washed and transferred to caffeine-free medium after 1, 2 and $3 \mathrm{~h}$ of incubation in the presence of caffeine, penetration rates were $14 \%, 76 \%$ and $94 \%$, respectively. Addition of caffeine to the fertilization medium caused as much as a 1.4-fold elevation in levels of cyclic AMP in sperm, the effect being maximal within about $0.5 \mathrm{~h}$ of incubation. These results indicate that during 2 to $3 \mathrm{~h}$ of incubation with oocytes in the caffeine-containing medium, the spermatozoa become highly fertile, and that a high concentration of cyclic AMP in sperm might not have any direct effects on the ability of sperm to penetrate oocytes.
\end{abstract}

Key words: Pig oocytes, In-vitro fertilization, Cyclic AMP, Spermatozoa.

(J. Reprod. Dev. 39: 347-352, 1993)

S uccessful in vitro fertilization of in vivo matured $S$ pig oocytes [1-3] has been reported. In such experiments, caffeine, a methylxanthine, was shown to be essential for the induction of the acrosome reaction, which results in the penetration of oocytes by sperm. Hyne and Garbers [4] reported that addition of 1-methyl-3isobutylxanthine, together with the presence of $\mathrm{Ca}^{2+}$ ions in the culture medium induced the acrosome reaction in capacitated guinea-pig sper-

Accepted for Publication: July 12, 1993

Correspondence: T. Nagai matozoa. They suggested that the increase in concentrations of cyclic AMP in sperm was related to the induction of the acrosome reaction. However, the mechanisms involved in these processes have not been clarified [4, 5].

In this study, the concentrations of cyclic AMP in sperm incubated in the presence and in the absence of caffeine were determined, and the effect of caffeine on in vitro fertilization of pig follicular oocytes was examined. 


\section{Materials and Methods}

\section{Culture of follicular oocytes}

Oocyte-cumlus complexes from crossbred gilts of the Landrace, Large White and Duroc breeds were collected, washed and cultured as previously described [6].

\section{Preparation of sperm}

Epididymal spermatozoa were frozen, thawed and preincubated as previously described [3] with the single exception that the duration of incubation of the spermatozoa was $70 \mathrm{~min}$ and the concentration of spermatozoa during the incubation was $4-5 \times 10^{8}$ cells $/ \mathrm{ml}$.

Assessment of penetration of oocytes after prefertilization incubation of sperm

About $10 \mu \mathrm{l}$ of the pre-incubated suspension of sperm was introduced into the fertilization medium (90 $\mu \mathrm{l}$ of Brackett and Oliphant solution with or without $2 \mathrm{mM}$ caffeine) [7] and incubated (prefertilization incubation) for $2 \mathrm{~h}$ under an atmosphere of $5 \% \mathrm{CO}_{2}$ in air at $39 \mathrm{C}$ before insemination. Oocytes were cultured for $46-48 \mathrm{~h}$ as described above, and then the cumulus cells were removed and the oocytes were transferred to the control fertilization medium $(90 \mu \mathrm{l})$ or to the same medium supplemented with $2 \mathrm{mM}$ caffeine. After the prefertilization incubation, a portion (about $10 \mu \mathrm{l}$ ) of each of the suspensions of sperm was introduced into the fertilization medium that contained oocytes so that the final concentration of spermatozoa at insemination was $4-5 \times 10^{5}$ cells/ $\mathrm{ml}$. The oocytes were incubated for $5 \mathrm{~h}$ with spermatozoa at $39 \mathrm{C}$ and then transferred to modified BMOC-2 medium [8]. Spermatozoa were then removed from the surface of the oocytes by pipetting. The oocytes were transferred to $100 \mu \mathrm{l}$ of the same medium and incubated for $5 \mathrm{~h}$ under the same conditions. After incubation, oocytes were fixed, stained and examined as previously described [9].

\section{Assessment of penetration by sperm during in-} semination

After the preincubation, a portion (about $10 \mu \mathrm{l}$ ) of each suspension of sperm was diluted in fertilization medium $(90 \mu \mathrm{l})$ that contained $2 \mathrm{mM}$ caffeine and then $10 \mu \mathrm{l}$ of each of these suspensions was introduced into the fertilization medium that contained oocytes so that the final concentration of spermatozoa at insemination was $4-5 \times 10^{6}$ cells $/ \mathrm{ml}$. After incubation for 1,2 and $3 \mathrm{~h}$ with spermatozoa at $39 \mathrm{C}$, oocytes were transferred to fresh fertilization medium without caffeine and treated as follows. Two-thirds of the inseminated oocytes were washed, with three changes of medium. A large-bore pipette was used in order to avoid removal of spermatozoa that were attached to the surface of the zona of oocytes. Then the oocytes were transferred to fertilization medium with or without caffeine. Spermatozoa were removed completely from the surface of the rest of inseminated oocytes by pipetting. After washing, these oocytes were transferred to the medium without caffeine. All the oocytes were subsequently incubated in fertilization medium such that the total duration of culture was $5 \mathrm{~h}$. Then oocytes were transferred to modified BMOC-2 medium and treated as described above. After incubation, oocytes were fixed, stained and examined as previously described [9].

\section{Determination of levels of cyclic AMP in sperm}

A portion (about $20 \mu \mathrm{l}$ ) of the pre-incubated suspension of sperm was introduced into the fertilization medium (180 $\mu \mathrm{l})$. After $0,0.5,1$ and 2 $\mathrm{h}$ of incubation under the same conditions as described above, $50 \mu \mathrm{l}$ of the suspension of sperm were pipetted into $1 \mathrm{ml}$ of ice-cold $6 \%$ trichloroacetic acid (TCA), and the mixture was homogenized by sonication. The homogenate was centrifuged at $500 \times \mathrm{g}$ for $15 \mathrm{~min}$ and the supernatant was collected. One milliliter of ice-cold 6\% TCA was added to the pellet, and cyclic AMP was extracted again as described above. After removal of TCA from the supernatant by washing with saturated ethylether, the cyclic AMP was quantitated by radioimmunoassay using a radioimmunoassay kit (New England Nuclear, Dupon, Japan).

\section{Statistics}

Data were analyzed by the $\chi^{2}$-test.

\section{Results}

Almost all the oocytes had undergone germinal vesicle breakdown (91-100\%). As shown in Table 1 , when oocytes were inseminated with the sper- 
matozoa in the presence of caffeine, the penetration rates were significantly higher $52 \%$ for the spermatozoa preincubated in the presence of caffeine and $62 \%$ for the spermatozoa preincubated in the absence of caffeine) than when oocytes were inseminated with spermatozoa in the absence of caffeine (2\% and $7 \%$, respectively).

As shown in Table 2, when inseminated oocytes were washed by a gentle pipetting and subsequently cultured in the presence of caffeine, the penetration rates were high $(85 \%$ to $98 \%)$ without regard to the duration of insemination ( 1 to $3 \mathrm{~h}$ ). However, when the washed oocytes were cultured in the absence of caffeine, the rate of penetration of oocytes that were incubated with sperm for $1 \mathrm{~h}$ was significantly lower (14\%) than in the case of 2 and 3 -h incubations ( $76 \%$ and $94 \%$, respectively). Moreover, when the inseminated oocytes were pipetted to remove the attached spermatozoa after 1 and $2 \mathrm{~h}$ of incubation with sperm, the rates of

Table 1. Effects of caffeine in the prefertilization ${ }^{\text {a }}$ medium on penetration by spermatozoa of oocytes

\begin{tabular}{ccccc}
\hline $\begin{array}{l}\text { Prefertilization } \\
\text { incubation of } \\
\text { spermatozoa in } \\
\text { presence }(+) \text { or } \\
\text { absence }(-) \text { of } \\
\text { caffeine } \\
(2 \mathrm{mM})\end{array}$ & $\begin{array}{c}\text { Fertilization } \\
\text { in presence } \\
(+) \text { or absence } \\
(2 \mathrm{mM})\end{array}$ & $\begin{array}{c}\text { No. of } \\
\text { oocytes } \\
\text { examined }\end{array}$ & $\begin{array}{c}\text { No. of } \\
\text { maturing } \\
\text { oocytes }^{\mathrm{b}} \\
\text { at }\end{array}$ & $\begin{array}{c}\text { No. of } \\
\text { oocytes } \\
\text { penetrated } \\
(\%)^{\mathrm{c}}\end{array}$ \\
\hline+ & & & $\begin{array}{c}\text { examination } \\
(\%)\end{array}$ & \\
+ & + & 69 & $65(94)$ & $34(52)^{\mathrm{d}}$ \\
- & - & 66 & $60(91)$ & $1(2)^{\mathrm{e}}$ \\
- & + & 47 & $47(100)$ & $29(62)^{\mathrm{d}}$ \\
& - & 48 & $45(94)$ & $3(7)^{\mathrm{e}}$ \\
\hline
\end{tabular}

${ }^{a}$ After preincubation for $70 \mathrm{~min}$ in TCM199 ( $\mathrm{pH} \mathrm{7.8),} \mathrm{spermatozoa} \mathrm{were} \mathrm{incu-}$ bated in fertilization medium for $2 \mathrm{~h}$ before insemination.

${ }^{\mathrm{b} O o c y t e s ~ t h a t ~ u n d e r w e n t ~ g e r m i n a l ~ v e s i c l e ~ b r e a k d o w n ~(G V B D) . ~}$

'Percentage of maturing oocyte.

${ }^{\mathrm{d}, \mathrm{e}}$ Numbers with different superscripts are significantly different $(\mathrm{P}<0.05)$.

Table 2. Effects of caffeine in the fertilization medium on penetration by spermatozoa of oocytes

\begin{tabular}{|c|c|c|c|c|c|}
\hline $\begin{array}{l}\text { Duration } \\
\quad \text { of } \\
\text { incu- } \\
\text { bation } \\
\text { with } \\
\text { sperm }^{\text {a }}\end{array}$ & $\begin{array}{l}\text { Pipetting } \\
\text { of } \\
\text { insemi- } \\
\text { nated } \\
\text { oocytes }\end{array}$ & $\begin{array}{l}\text { Culture of } \\
\text { fertilized } \\
\text { oocytes } \\
\text { in presence } \\
(+) \text { or absence } \\
(-) \text { of caffeine } \\
(2 \mathrm{mM})\end{array}$ & $\begin{array}{c}\text { No. of } \\
\text { oocytes } \\
\text { examined }\end{array}$ & $\begin{array}{l}\text { No. of } \\
\text { maturing } \\
\text { oocytes } \\
\text { at } \\
\text { exami- } \\
\text { nation }\end{array}$ & $\begin{array}{c}\text { No. of } \\
\text { oocytes } \\
\text { penetrated } \\
(\%)^{d}\end{array}$ \\
\hline \multirow[t]{3}{*}{1} & - & + & 34 & $34(100)$ & $29(85)^{\mathrm{fg}}$ \\
\hline & - & - & 118 & $118(100)$ & $16(14)^{\mathrm{i}}$ \\
\hline & + & - & 119 & $116(98)$ & $0(0)$ \\
\hline \multirow[t]{3}{*}{2} & - & + & 110 & $109(99)$ & $98(90)^{\mathrm{f}}$ \\
\hline & - & - & 102 & $100(98)$ & $76(76)^{\mathrm{g}}$ \\
\hline & + & - & 101 & $96(95)$ & $18(19)^{\mathrm{i}}$ \\
\hline \multirow[t]{3}{*}{3} & - & + & 131 & $129(99)$ & $128(98)^{e}$ \\
\hline & - & - & 103 & $101(98)$ & $95(94)^{\mathrm{f}}$ \\
\hline & + & - & 107 & $107(100)$ & $66(62)^{\mathrm{h}}$ \\
\hline
\end{tabular}

${ }^{a}$ Oocytes were inseminated with preincubated spermatozoa in fertilization medium that contained caffeine $(2 \mathrm{mM})$ for the indicated time.

${ }^{\mathrm{b}}$ The inseminated oocytes were freed of attached spermatozoa by vigorous pipetting $(+)$ or washed by gentle pipetting $(-)$.

'Oocytes that underwent germinal vesicle breakdown.

${ }^{\mathrm{d}}$ Percentage of maturing oocytes.

e,f,g,h,i Numbers with different superscripts are significantly different $(P<0.05)$. 


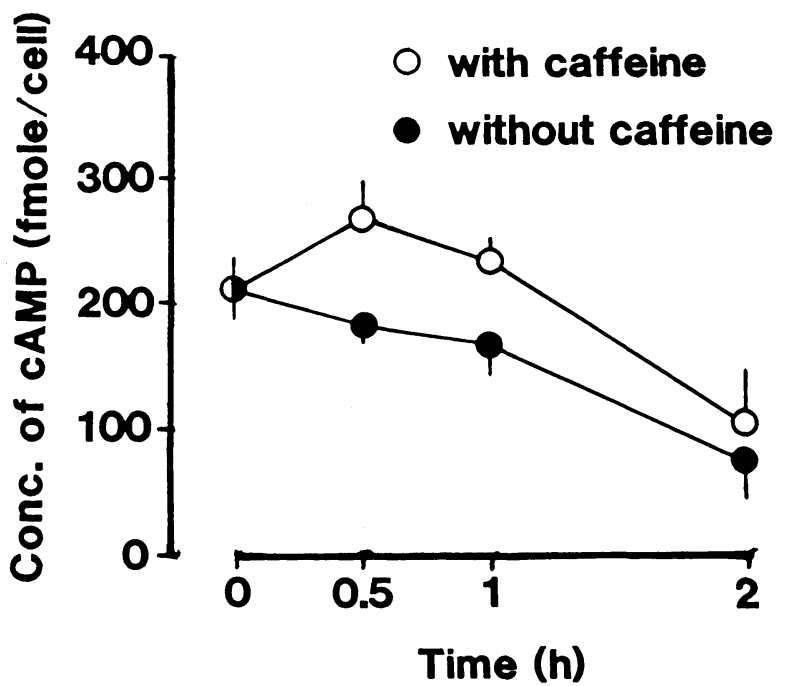

Fig. 1. Effects of caffeine on concentrations of cyclic AMP in sperm. Preincubated spermatozoa were incubated in fertilization medium with or without $2 \mathrm{mM}$ caffeine for the indicated times. Results are means \pm SE from three replicates.

penetration were significantly reduced $(0 \%$ and $19 \%$, respectively). However, after a 3 -h incubation with sperm, the rate returned to a high value $(62 \%)$.

As shown in Fig. 1, when preincubated spermatozoa were subsequently incubated in fertilization medium that contained caffeine, concentrations of cyclic AMP in sperm after $0.5,1$ and $2 \mathrm{~h}$ of culture were higher $(267 \pm 27,234 \pm 14$ and $107 \pm 41$ fmole/cell, respectively) than when they were incubated in the medium in the absence of caffeine $(183 \pm 13,171 \pm 17$ and $77 \pm 28$ fmole/cell, respectively; means \pm SE: $n=3$ ).

\section{Discussion}

Methylxanthines are effective stimulators for the in-vitro fertilization in many mammalian species; e.g., pig [1-3], man [4], cattle [11], guinea pig [4] and mouse [12]. Fraser [12] demonstrated that caffeine significantly decreased the capacitation time for mouse spermatozoa and that it promoted rapid penetration of eggs. Our results indicate that caffeine also promotes penetration by sperm of pig oocytes matured in vitro.

To examine the effects of caffeine on the ability of spermatozoa to penetrate oocytes, preincubated spermatozoa were incubated for $2 \mathrm{~h}$ (prefertilization incubation) in fertilization medium in the presence or in the absence of caffeine. Thereafter, the incubated spermatozoa were introduced into fertilization medium (with or without caffeine) that contained oocytes. If spermatozoa were fully capacitated during the prefertilization incubation in the presence of caffeine, they would be able to penetrate the oocytes in the caffeine-free medium. However, the spermatozoa that were incubated in the caffeine-containing medium penetrated only $2 \%$ of oocytes when the oocytes were inseminated in caffeine-free medium. Given that penetration rates were quite high $(52 \%$ and $62 \%)$ in the case of oocytes inseminated in caffeine-containing medium, independently of the presence or absence of caffeine during the prefertilization incubation of sperm, it appears that a 2 -h prefertilization incubation in caffeine-containing medium was not sufficient for the capacitation of spermatozoa. Alternatively, caffeine might promote the capacitation and/or the acrosome reaction of spermatozoa only in the presence of oocytes, that is to say, in the presence of zona pellucida. Critser et al. [13] reported that pretreatment of bovine spermatozoa with caffeine prior to insemination of oocytes did not increase the frequency of either the acrosome reaction or fertilization during incubation of sperm and oocytes, but they did not examine the effect of caffeine in the fertilization medium on penetration by sperm.

Following our observations of penetration by sperm of oocytes in fertilization medium that contained caffeine, we extended our studies to examine conditions that promoted penetration of oocytes by sperm. When oocytes were incubated with preincubated spermatozoa for $2 \mathrm{~h}$ in caffeinecontaining medium and transferred to caffeinefree medium with spermatozoa attached to the zona, $76 \%$ of them were penetrated (Table 2). By contrast, when inseminated oocytes were freed of attached spermatozoa after a 2-h of incubation with sperm and then transferred to caffeine-free medium, the rate of penetration was significantly reduced $(19 \%)$. It appeared that some spermatozoa had completed the process of capacitation and the acrosome reaction and had penetrated zona pellucida within the 2-h of incubation and that the spermatozoa that had attached to the zona during that time were able to penetrate oocytes in caffeine-free medium. However, if oocytes were incubated with spermatozoa for an additional hour in the presence of caffeine, the rate of 
penetration rose considerably $(62 \%)$. These results indicate that during 2 to $3 \mathrm{~h}$ of incubation with oocytes in the caffeine-containing medium the spermatozoa become highly fertile.

Although the mechanisms that control the production of cAMP in sperm are poorly understood [5], it was found that caffeine, a phosphodiesterase inhibitor, can elevate the concentration of cAMP in sperm (Fig 1). Treatments that should raise intracellular levels of cAMP promote fertilization in vitro in many mammalian species (reviewed by Fraser and Monks [5]). While the mechanism involved in this effect of cAMP on capacity of spermatozoa to fertilize oocytes is not clear, Fraser and Monks [5] suggested that high levels of cAMP may promote development of the hyperactivated motile sperm that are necessary for penetration of the zona pellucida. However, in the present experiments, no hyperactivated motile sperm were observed. In fact, the motility of the frozen and thawed epididymal spermatozoa was so low, as compared with that of freshly ejaculated spermatozoa, that only straight forward movements were observed. Given that the effect of caffeine on the concentration of cAMP was evident within only 0.5 $h$ of incubation, while the effect of caffeine on the ability of sperm to penetrate oocytes was slow in developing and not evident until 2 to $3 \mathrm{~h}$ had elapsed, it is suggested that cyclic AMP might not influence the ability of sperm to fertilize oocytes directly. Thus, the effect of caffeine on sperm might be mediated by factors other than cyclic AMP or might be triggered by cyclic AMP.

It is of interest that the sperm acrosome reaction is associated with both the primary transport of $\mathrm{Ca}^{2+}$ ions and $\mathrm{a} \mathrm{Ca}^{2+}$-dependent increase in concentrations of cyclic AMP in guinea-pig sperm [4]. Moreover, significantly higher levels of cyclic
AMP were found in hamster spermatozoa incubated in the presence of calcium than in its absence [14]. In addition, Kopf et al. [15-17] reported that methylxanthines elevate concentrations of cyclic AMP in abalone sperm and induce the acrosome reaction. They suggested that the methylxanthineinduced acrosome reaction was mediated by a primary effect on the transport of $\mathrm{Ca}^{2+}$ ions and occurred through a verapamil-sensitive mechanism. They also reported that methylxanthines can affect the acrosome reaction via primary effects on the transport of $\mathrm{Ca}^{2+}$ ions and changes in $\mathrm{Ca}^{2+}$ conductance [17]. Furthermore, Okamura et al. [18] showed that when boar epididymal spermatozoa are incubated with or without caffeine in the presence of ${ }^{45} \mathrm{CaCl}_{2}$, incubation with caffeine results in a higher level of sperm-associated ${ }^{45} \mathrm{Ca}^{2+}$ ions as compared to that in spermatozoa incubated without caffeine. Therefore, it is suggested that caffeine might promote the association of external $\mathrm{Ca}^{2+}$ ions with spermatozoa and that the increased level of $\mathrm{Ca}^{2+}$ ions might induce the acrosome reaction when the spermatozoa are attached to the zona pellucida. Recently, it was shown that solubilized zona pellucida can bind to the acrosome of the boar spermatozoa when caffeine and $\mathrm{Ca}^{2+}$ ions are present in the incubation medium [19]. Furthermore, zona proteins have been reported to induce the acrosome reaction of ejaculated boar spermatozoa [20].

\section{Acknowledgements}

The research was supported in part by a grant-in-aid (Bio Media Program) from the Japanese Ministry of Agriculture, Forestry and Fisheries (BMP 93-II-1-7).

\section{References}

1. Cheng WTK, Moor RM, Polge C. In vitro fertilization of pig and sheep oocytes matured in vivo and in vitro. Theriogenology 1986; 25: 146 (Abstract).

2. Yoshida M. In vitro fertilization of pig oocytes matured in vivo. Japan J Vet Sci 1987; 49: 711-718.

3. Nagai T, Takahashi T, Masuda H, Shioya $\mathbf{Y}$, Kuwayama M, Fukushima M, Iwasaki S, Hanada A. In vitro fertilization of pig oocytes by frozen boar spermatozoa. J Reprod Fert 1988; 84: 585-591.
4. Hyne RV, Garbers DL. Calcium-dependent increase in adenosine 3', 5'-monophosphate and induction of the acrosome reaction in guinea-pig spermatozoa. Proc Natl Acad Sci USA 1979; 76: 5699-5703.

5. Fraser LR, Monks NJ. Cyclic nucleotides and mammalian sperm capacitation.J Reprod Fert 1990; 42 (suppll): 9-21.

6. Nagai T, Moor RM. Effect of oviduct cells on the 
incidence of polyspermy in pig eggs fertilized in vitro. Mol Reprod Develop 1991; 26: 377-382.

7. Brackett BG, Oliphant G. Capacitation of rabbit spermatozoa in vitro. Biol Reprod 1975; 12: 260-274.

8. Brinster RL. Studies on the development of mouse embryos in vitro. J Reprod Fertil 1965; 10: 227-240.

9. Nagai $\mathbf{T}$, Niwa $K$, Iritani A. Effect of sperm concentration during preincubation in a defined medium on fertilization in vitro of pig follicular oocytes. I Reprod Fert 1984; 70: 271-275.

10. Aitken RJ, Best F, Richardson DW, Schato R, Simm G. Influence of caffeine on movement characteristics, fertilizing capacity and ability to penetrate cervica mucus of human spermatozoa. $J$ Reprod Fert 1984; 75: 19-27.

11. Hanada A, Suzuki T, Shioya Y. Birth of calves from non-surgical transfer of blastocysts originated from in vitro fertilized oocytes matured in vitro. In: Program of 78th Annul meeting of Japan Soc Zootech Sci. 1986: 79 (Abstract) (In Japanese).

12. Fraser LR. Accelerated mouse sperm penetration in vitro in the presence of caffeine. J Reprod Fert 1979; 57: 377-384.

13. Critser ES, Leibfried ML, First NL. The effect of semen extension, cAMP and caffeine on in vitro fertilization of bovine oocytes. Theriogenology 1984; 21: 625-631.

14. White DR, Aitken RJ. Relationship between cal- cium cyclic AMP, ATP and intracellular $\mathrm{pH}$ and the capacity of hamster spermatozoa to express hyperactivated motility. Gamete Res 1989; 22: 163-177.

15. Kopf GS, Lewis CA, Vacquier VD. Regulation of abalone sperm cyclic AMP concentrations and the acrosome reaction by calcium and methylxanthines. Dev Biol 1983; 98: 28-36.

16. Kopf GS, Lewis CA, Vacquier VD. Methylxanthines stimulate calcium transport and inhibit cyclic nucleotide phospho-diesterases in abalone sperm. Dev Biol 1983; 99: 115-120.

17. Kopf GS, Lewis CA, Vacquier VD. Characterization of basal and methylxanthine-stimulated $\mathrm{Ca}^{2+}$ transport in abalone spermatozoa. J Biol Chem 1984; 259: 5514-5520.

18. Okamura N, Fukuda A, Tanba M, Sugita Y, Nagai T. Changes in the nature of calcium transport systems on the porcine sperm plasma membrane during epididymal maturation. Biochim Biophys Acta 1992; 1108: 110-114.

19. Hatanaka $\mathbf{Y}$, Nagai $\mathbf{T}$, Tobita $\mathbf{T}$, Nakano $\mathbf{N}$. Changes in the properties and composition of zona pellucida of pigs during fertilization in vitro. $J$ Reprod Fert 1992; 95: 431-440.

20. Berge T, Turner KO, Meizel S, Hedrick JL. Zona pellucidainduced acrosome reaction in boar sperm. Biol Reprod 1989; 40: 525-530. 